\title{
Fostering Inclusion of Disabled Youth Through Young Adult Literature: Action Research with Wonder
}

\author{
Judith A. Hayn, University of Arkansas at Little Rock \\ Karina R. Clemmons, University of Arkansas at Little Rock \\ Heather A. Olvey, University of Arkansas at Little Rock
}

If I found a magic lamp and I could have one wish, I would wish that I had a normal face that no one ever noticed at all. I would wish that I could walk down the street without people seeing me and then doing that look-away thing. Here's what I think: the only reason I'm not ordinary is that no one else sees me that way. (August Pullman, p. 3)

Ten-year old Auggie Pullman wants to be ordinary; he does ordinary child activities such as eating ice cream and playing on his Xbox. But no matter how much he wants to be ordinary, he cannot be. Other kids run screaming from him, and he encounters stares wherever he goes. Auggie was born with a severe craniofacial abnormality, and in an effort to protect him, his parents home-schooled him. Now as he begins middle school, he is enrolling in Beecher Prep, a private school, in New York City.

Wonder (2012) by R. J. Palacio is the story of Auggie's fifth grade year, told partly from his perspective and partly from the viewpoints of others in his life - Auggie's sister Via and her oldest friend Miranda; Via's boyfriend Justin; Jack, who is recruited to be Auggie's new friend at Beecher Prep; and Summer, who seeks out Auggie's friendship of her own accord. Each narrator has a distinct, authentic voice, while Palacio's balance of humor and pathos makes each character imperfect yet sympathetic. Palacio brings life to the adolescent characters with expressive descriptions of how the characters think, how they talk, and how they have the capacity to be both horribly mean and incredibly brave and kind. The short chapters and shifting narrative yield a quick, easy read, one to share with middle school students and their future teachers. Recent studies have effectively used young adult literature (YAL) as an intervention to engage readers and change attitudes related to issues of social justice (Clemmons, Hayn, \& 
Olvey, 2014; Hayn, Clemmons, \& Garner, 2013; Hill, 2009), so the authors were inspired to use Wonder to conduct an action research project with pre-service teachers.

\section{Difficulties Facing Disabled Adolescents at School}

Multiple models of disability have shaped our understanding of persons with disabilities (Garrison, 2007). Some of these models prove particularly damaging to persons with disabilities. The freak model of disability, for instance, "assumes a person with a disability is not capable of improving or becoming normal and their appearance or behavior is looked upon as a spectacle and deviant" (Garrison, 2007, p. 11). This model of disability, like the charity and medical models, assumes that the disabled person is deficient in some way. The freak model also stresses the "sociocultural meaning attributed to physiological conditions" (Longmore \& Goldberger, 2000 , p. 892); it shows how society uses physical disabilities to judge - or even to discount individuals' capacity and intelligence.

Nachowitz (2015) noted, "Participation in class discussion and, subsequently, the collaborative construction of knowledge about texts is difficult for many students but even more so for students who may have several years of self-doubt struggling with literacy, keeping pace with other students, and especially for those who are labeled special needs" (p. 35). Students with disabilities are at a higher risk for negative social interactions outside the classroom. As Humphrey and Symes (2010) say, "Within the social environment of high school, difficulties in the areas of communication and social interaction can put students with ASD [autism spectrum disorders] at risk for social isolation and bullying" (p. 65).

Teachers' attitudes can exacerbate the issues students with disabilities must overcome. Hedges et al. (2014) indicated that teachers reported feeling unprepared, unknowledgeable, and unsupported when dealing with students who have disabilities. Davis, Cook, and Ostenson (2015) asserted that labeling students with one disorder or another perpetuated the stigma attached to these students, and they instead suggested that teachers empower students with constructivist and self-directed learning. When writing to present the research study findings regarding the effects of labeling for special education students, Stacie Marsh (2008) stated that,

"Teacher attitudes towards students labeled with disabilities play a critical role in the success of student achievement in the general curriculum" (p.2). 


\section{Literature as Catalyst for Change}

Our action-research model of using YAL to change perceptions on timely and relevant issues was based on recent studies investigating the effectiveness of YAL to increase empathy on various social-justice issues (Hayn, Clemmons, \& Garner, 2013; Hill, 2009). Malo-Juvera (2014) examined how YAL affected adolescents' acceptance of rape myth. The study found that reading intervention can lower adolescents' rape-myth acceptance. The study's focus on YAL supports the idea that perceptions of important social issues can be addressed through YAL.

Cameron and Rutland (2006) conducted a six-week research study analyzing how nondisabled students were affected by reading books containing disabled characters. The results indicated that "this type of intervention could allow for widespread reduction in prejudice to occur without the need for everyone to have an outgroup friend" (Cameron \& Rutland, 2006, p. 470). Even more promising, the study showed that this type of intervention could be administered with positive results before inclusion of a new disabled student. Garrison (2008) looked at the effects of reading Steinbeck's Of Mice and Men using reader response theory so that students could understand disability through a sociocultural context, and he noted, "Awareness of disability as a sociocultural construct creates opportunities to explore how literature reflects propagates beliefs and values" (Garrison, p. 16).

Inclusion of students with disabilities into general education classrooms is not simply a requirement of the Individuals with Disabilities Act (IDEA); it is a matter of social justice. In their article "Facilitating Inclusion: Young Adult Literature as a Tool," Hayn, Hazlett, and Sweeney (2009) discuss the social rejection faced by disabled students and/or students with congenital conditions, and they detail the difficulty of building an accepting, open attitude in classrooms. Barriers to creating comfortable classroom climates that emphasize respect for all students are difficult to eliminate. Students' immaturity and desire for conformity compound the problem: often they bully or exclude individuals who look different or behave differently. Talking openly with non-disabled students about acceptance proves difficult. What can we do to integrate teens with their peers in authentic and meaningful ways without creating or exacerbating stigmas?

Andrews (1998) believes that reading literature about disabilities, followed by discussion, can be influential in helping non-disabled students develop awareness, understanding, and compassion. These experiences might even lead students to view individuals with disabilities 
more positively. Other authors support this position and use of young adult literature (YAL) to accomplish this, including Blasingame (2007), Christenbury (2006), Henderson (2009), Kennedy and Menten (2010), and Reid (2010).

In particular, Cart (2006) asserts that all of us are aware of disabled students, but schools seldom have plans to deal with them. He affirms that many disabled students are still ignored, patronized, bullied, or otherwise stigmatized by classmates. Understanding what disabled students endure is crucial for individuals who are no disabled. As Cart eloquently states, "Kids need to learn empathy. They need to learn how the other can become $u s^{\prime \prime}$ (p. x). Cart believes that a viable way for students to learn empathy is "through reading fiction that capturesartfully, authentically, and unsparingly — the circumstances of kids" (p.xiii) who are in such situations.

Ball and Green (2014) conducted a study on school leaders' attitudes regarding inclusion of students with disabilities; the study sought to establish a link among training, attitudes, and practices of educational leaders related to students with disabilities. The 170 participants reported that students with disabilities constituted 5\%-20\% of their student bodies. This statistic is consistent with the U.S. Department of Education's (2011) reports: roughly 12\% of students in public schools have disabilities, and of this group $90 \%$ spend at least some time in generaleducation classes. "According to the results of this study, there is a relationship between the training and experience of school leaders and their attitudes...Additionally, their attitudes toward the inclusion of students with disabilities were slightly negative" (Ball \& Green, p. 75). The results indicated that school leaders often focus on the level of disability when making placement choices. The researchers further noted, "Based on the data analysis, the more training and experience school leaders had, the more negative their attitudes were toward inclusion" (p. 70). The need for empathy and acceptance of students with disabilities becomes even more critical when we examine research supporting the claim that students who are included in general education settings typically fare better than those who are kept isolated in special education programs (Artiles, Harris, \& Rostenberg, 2006; McKlesky \& Waldon, 2011).

It is imperative that meaningful inclusion of students with disabilities is an issue upon which schools, administrators, and teachers must continue to improve (Artiles, Harris-Murri, \& Rostenberg, 2006, \& Cart, 2003). Kennedy and Menten (2010) believe that secondary classrooms are excellent platforms to use to discuss issues of disability in an attempt to bridge 
students to the place of empathy and understanding that Cart advocates. They state that working with secondary students on issues of disability "has the potential to transform assignments, activities, discussions, and curricula to better acknowledge and reflect on the realities of human differences and our basic assumptions about normalcy and abilities" (pp. 66-67). Reid (2010) cautions us to ensure that the books we choose have relatable and positive representations of characters with disabilities. These representations will help students with disabilities to build self-confidence and their peers to gain insight into the life experiences of people with disabilities.

In summary, Hayn, Hazlett, and Sweeney (2009) remind us:

The inclusion of literature where individuals with disabilities, conditions, and/or illnesses are portrayed as functional, independent, and proactive role models in realistic settings is one positive approach to achieving these desired goals; in so doing, we promote awareness, sensitivity, and tolerance of individual differences, while combating many of the issues related to peer and social rejection. (p. 9)

\section{Action Research Method}

Action research involves a practitioner's reflection upon professional practice and actively involves the researcher as a participant in the process of investigation in a specific setting (Stringer, 2013). According to Stringer (2013), "Unlike experimental or quantitative research that looks for generalizable explanations related to a small number of variables, action research seeks to engage the complex dynamics in any social context" (p.1). Thus, action research dynamically engages the practitioner as researcher to investigate, solve problems, and improve situations that are in a specific time, place, and context.

The authors of this article have previously examined changing attitudes among preservice teachers through the use of action research with YAL. Based on the results of previous studies, we believe that YAL could change preservice teachers' attitudes toward young teens with disabilities. Our model is based on the use of YAL to change perceptions about timely and relevant issues and was based on recent studies investigating the effectiveness of YAL to increase empathy on varied social justice issues (Clemmons, Hayn, \& Olvey, 2014; Hayn, Clemmons, \& Garner, 2013; Hill, 2009). With this goal in mind, we designed pre- and postreading surveys (Figure 2) to target candidates' awareness of disabilities and perceptions of teachers' responsibilities toward creating a safe and inclusive environment for all students. 
The survey was administered in a mid-size metropolitan research university in the MidSouth. After receiving the university's Institutional Review Board approval, the survey was administered before and after reading Palacio's Wonder (2012); participants had also engaged in a critical analysis of the text. The novel was required class reading in a combined undergraduate and graduate-level adolescent literature and literacy course one of the authors teaches, but participation in the pre- and post-reading surveys was entirely voluntary and was not tied to a grade for the class. A graduate assistant administered the survey and conducted the class activities and discussions that pertained to the book.

The survey questions were designed to measure teacher candidates in three different categories: teacher responsibility in the classroom regarding students with physical differences (questions 1, 2, 5, 7, and 9), knowledge of conditions that cause physical differences (questions 3,6 , and 8), and personal reactions of teacher candidates toward students with physical deformities (question 4 and the short answer question). These aforementioned categories were used in the creation of the survey, but they were not listed on the survey. A Likert scale of Agree (A), Disagree (D), and Unsure (U) was used for nine of the questions. A short-answer question concluded the pre-reading survey, and an additional short answer question was included on the post-reading survey.

Following the administration of the pre-reading survey, the class was instructed to read the book. After students had read the book, class time was then spent in open discussion and activities related to the book. The activities were designed to help the pre-service teachers learn the importance of discussing the challenges students with disabilities face with all of their future students. The activities also helped develop an understanding of the role teachers must play in creating a safe, inclusive, and comfortable environment for all students.

In the book, Auggie has a combination of a genetic disorder and Treacher-Collins syndrome, a genetic craniofacial abnormality that can cause many physical problems related to hearing, breathing, and swallowing. To tie the discussion of disabilities directly to Wonder, the first activity began with graduate assistant introducing Marcus Julinai's public, shareable Prezi presentation on Treacher-Collins syndrome (https://prezi.com/xvyv2qsj1feo/treacher-collinssyndrome/). The presentation contains two clips, one of which is narrated by an eleven-year-old boy with the syndrome. This video was particularly moving for the preservice teachers, and the class agreed that the video would be beneficial to use with students as a catalyst for discussion in 
classrooms. The video would allow students to become accustomed to seeing someone who looks very different from themselves, and it would illustrate that people with disfigurements and/or disabilities want and need the same types of things as people without them.

The opening presentation was followed by a group activity titled "Four Sides of the Story." Wonder tells its story from multiple characters' perspectives, which forms a more complete picture of the experience. The class focused on "the Halloween incident" in which Auggie shows up at school unrecognized in a mask and overhears his peers and friend Jack mocking him. Auggie, Via, Summer, and Jack all experience this incident differently, so the preservice teachers worked in groups to compare and contrast the different versions. Afterward, students shared their discoveries in a whole-group discussion. They reported that the different perspectives fostered empathy by demonstrating why people make different choices, and they showed how someone can easily fall into saying or doing something mean without necessarily intending to. Notably, the conversation shifted toward teacher responsibility in fostering inclusion, and the class discussed instances in the book when a teacher could have done something differently to prevent Auggie's discomfort.

After the class activities and discussion concluded, the post-reading survey was administered. The post-survey was analyzed alongside the pre-reading survey to determine if perceptions had changed and/or knowledge of the topic had increased.

\section{Results}

The current study included 14 participants, and there was no attrition across the course of the study. The small sample size should be noted as a limitation of this action research. The demographic information shows eight female and three male preservice teachers participating in the study, with ages ranging from 21-60+. There were eight participants that labeled themselves as white, and three labeled themselves as African-American. The academic majors were mostly English Language Arts, but as the activity was conducted in a course used as an elective, there were also majors in social studies, math, and French. Most of the participants reported having had some sort of interaction with people with a physical deformity, although two preservice teachers noted that they had not.

The categories of teacher responsibility, knowledge, and personal reaction were all considered in the data analysis. In the area of teacher responsibility, there was a clear shift in 
perceptions on all of the questions. The most dramatic change was seen on Question \#5, "When a student with a severe physical deformity attends a general education class for the first time, all of the students should be prepared ahead of time so that the students can ask questions and know what to expect." On the pre-survey three participants marked "Agree," four marked "Disagree," and seven marked "Unsure." On the post-survey 12 pre-service teachers marked "Agree," while only two marked "Unsure." This result indicates that the book made pre-service teacher participants realize the necessity of educating non-disabled students alongside disabled peers and thus creating a more comfortable, understanding environment.

Another dramatic shift in answers was discovered on Question \#9, "People with physical deformities feel ordinary to themselves; it is how other people treat them that make them feel different." On the pre-survey, only four participants marked "Agree“; however, on the post, ten participants agreed with this statement. These results indicate that the preservice teachers in the study experienced increased empathy and understanding for the experiences of students with disabilities.

In the category of knowledge of conditions that cause physical differences, there was a positive shift in knowledge acquisition across the questions. On the pre-survey few people knew about Treacher-Collins or craniofacial abnormalities, but by the post-survey all but one participant indicated a knowledge of both conditions. Before exposure to this study, only eight participants knew that severe physical deformities could cause other health issues, but by the post-survey 11 participants agreed.

Growth was also apparent in the short answer questions related to the personal reaction category. The first short-answer question on the post-survey asked participants to think about the situation they wrote about on the pre-survey and to analyze the experience again after reading Wonder. After reading the book, one participant wrote, "When encountering someone with severe physical deformity I panic inside ... I don't think that will change, but outwardly, I know how to handle it better." Another preservice teacher stated, "Now that I have read Wonder, I have a greater sense or understanding. I feel people [with disabilities] should be treated with the same kind of respect and encouragement." Showing increased personal reflection, one participant noted, "Now that I have read Wonder I know my reaction to the angry soldier with the facial scarring wasn't exactly the right way of handling it. Ignoring the problem doesn't aid in it's [sic] solution." A final comment that highlights one participant's insight is, “As I look 
back at the situation, I wish I would have been more open and gotten to know him better before I pre-judged him based on his looks."

The final short answer question, "Write comments and reflections about your knowledge and experiences after reading Wonder and participating in course activities and discussions related to the book," allowed participants to comment on any aspect of either the book itself or their thoughts about related issues. Responses included preservice teachers' ideas for integrating the book in their future classes and their commitment to including people with disabilities and fostering empathy and acceptance from non-disabled students. One participant stated, "I do know I am better prepared to reflect w/ [sic] students about differences between each other and how to foster acceptance in the classroom."

\section{Conclusion}

The results of this action research, even given its small sample size, add to the growing body of research demonstrating the efficacy of YAL in the classroom. The perception of preservice teachers' attitudes toward disabilities showed positive changes, and this study serves as a call to action for teachers to search for quality YAL that can effectively teach social-justice issues. A list of YAL containing themes related to disability is listed in Figure 1. The participants in this study noted that they feel better able to address issues of disabilities and/or physical deformities as a result of their exposure to Wonder and the class discussions and activities, which was the hope of the authors.

Wonder is the consummate text for addressing discomfort regarding physical difference. What can teachers do to help their students learn how to "choose kindness"? A National Public Radio (NPR) story (2013) reports that Palacio's book has made an impact and been embraced by towns, schools, and the craniofacial community. This action research adds to a growing body of evidence demonstrating the power of YAL to change perceptions. The results demonstrate that reading the book positively impacted preservice teachers, and they suggest the potential power that the book can have with teens. A list of additional resources for teaching acceptance of individuals with disabilities is contained in Figure 3. As one candidate noted, "From reading Wonder I've learned to see things from other's perspectives, and to get to know people instead of pushing people aside because they're different from me." This statement is an endorsement 
indicating that quality YAL can, in fact, change people's perceptions and help them become more empathetic to people who are different from themselves.

Figure 1

Additional YAL Texts Including Characters with Disabilities

\begin{tabular}{|l|l|l|}
\hline Book Title (Publication Year) & Author & Themes \\
\hline My Thirteenth Winter (2005) & Samantha Abeel & Learning disability \\
\hline Part-Time Indian (2009) & Sherman Alexie & Hydrocephalus \\
\hline Pinned (2014) & Sharon G. Flake & Wheelchair confined \\
\hline The Fault in Our Stars (2014) & John Green & $\begin{array}{l}\text { Limited by cancer, loss of } \\
\text { sight }\end{array}$ \\
\hline Dangerous (2014) & Shannon Hale & $\begin{array}{l}\text { Limitation with only one } \\
\text { hand }\end{array}$ \\
\hline Accidents of Nature (2006) & $\begin{array}{l}\text { Harriet McBryde } \\
\text { Johnson }\end{array}$ & Cerebral palsy \\
\hline A Mango-Shaped Space (2005) & Wendy Mass & Synesthesia \\
\hline The Elementals (2014) & Saundra Mitchell & Disabilities from polio \\
\hline $\begin{array}{l}\text { The Beginning of Everything } \\
\text { (2014) }\end{array}$ & Robyn Schneider & Physical disability \\
\hline Inside Out (2004) & Terry Trueman & Emotional disabilities \\
\hline
\end{tabular}


Figure 2

\section{Pre-/Post- Survey Questions}

Directions: After reading each question circle "Agree," "Disagree," or "Unsure."

\begin{tabular}{|c|c|c|c|}
\hline $\begin{array}{l}\text { 1. If I overheard a student making a derogatory remark } \\
\text { about another student's appearance I would reprimand the } \\
\text { student. }\end{array}$ & Agree & Disagree & Unsure \\
\hline $\begin{array}{l}\text { 2. Educators who work with students with physical } \\
\text { deformities should make an effort to highlight those } \\
\text { students' strengths. }\end{array}$ & Agree & Disagree & Unsure \\
\hline $\begin{array}{l}\text { 3. I am familiar with the term "Treacher-Collins } \\
\text { Syndrome." }\end{array}$ & Agree & Disagree & Unsure \\
\hline $\begin{array}{l}\text { 4. I sometimes initially assume that people with physical } \\
\text { deformities have mental problems. }\end{array}$ & Agree & Disagree & Unsure \\
\hline $\begin{array}{l}\text { 5. When a student with a severe physical deformity } \\
\text { attends a general education class for the first time, all of } \\
\text { the students should be prepared ahead of time so that the } \\
\text { students can ask questions and know what to expect. }\end{array}$ & Agree & Disagree & Unsure \\
\hline $\begin{array}{l}\text { 6. People with severe physical deformities may have } \\
\text { many health issues as a result of their condition. }\end{array}$ & Agree & Disagree & Unsure \\
\hline $\begin{array}{l}\text { 7. Students with severe physical deformities should be } \\
\text { allowed to share their story with other students in an effort } \\
\text { to increase understanding. }\end{array}$ & Agree & Disagree & Unsure \\
\hline 8. I am familiar with the term "craniofacial abnormality." & Agree & Disagree & Unsure \\
\hline $\begin{array}{l}\text { 9. People with physical deformities feel ordinary to } \\
\text { themselves; it is how other people treat them that make } \\
\text { them feel different. }\end{array}$ & Agree & Disagree & Unsure \\
\hline
\end{tabular}

Explain a situation in which you have come into contact with a person with a severe physical deformity. Share something about the situation and the person. What were your thoughts? How did you react? 


\section{Post-reading survey questions:}

How do you feel when you reflect back on the previously mentioned experience now that you have read Wonder?

Write comments and reflections about your knowledge and experiences after reading Wonder and participating in course activities and discussions related to the book.

Figure 3

\section{Additional Resources}

1. http://rjpalacio.com/for-teachers.html

The author of Wonder has provided questions for teachers to think about and discuss with regards to the book. Many of the questions relate to the themes of inclusion and acceptance.

2. The Julian Chapter: A Wonder Story

Pluto: A Wonder Story

Shingaling: A Wonder Story

Palacio has continued to develop Auggie's story by writing several Kindle singles from the perspectives of Julian, Auggie's childhood friend Christopher, and Charlotte.

3. http://www.treachercollins.org/tcs/Welcome.html

This website offers resources, pictures, and essays by and about people with TreacherCollins syndrome. One can learn much about the syndrome, and even more about people with disfigurements and/or disabilities in general by reading the personal stories and essays. 
References

Andrews, S. E. (1998). Using inclusion literature to promote positive attitudes toward disabilities. Journal of Adolescent and Adult Literacy, 41(6), 420-426.

Artiles, A. J., Harris-Murri, N., \& Rostenberg, D. (2006). Inclusion as social justice: Critical notes on discourses, assumptions, and the road ahead. Theory into Practice, 45(3), 260268.

Ball, K., \& Green, R. L. (2014). An investigation of the attitudes of school leaders toward the inclusion of students with disabilities in the general education setting. National Forum of Applied Educational Research Journal, 21(1\&2), 57-76.

Blasingame, J. (2007). Books that don't bore 'em. New York: Scholastic.

Cameron, L., \& Rutland, A. (2006). Extended contact through story reading in school: Reducing children's prejudice toward the disabled. Journal of Social Issues, 62(3), 469-488.

Cart, M. (2006). Necessary noise: Stories about our families as they really are. New York, NY: Harper Teen.

Christenbury, L. (2006). Making the journey: Being and becoming a teacher of English language arts. Portsmouth, NH: Heinemann.

Clemmons, K. R., Hayn, J. A., \& Olvey, H. A. (2014). Increasing awareness of cybersafety \& teacher responsibility with YA lit: Action research with Want to Go Private? Florida English Journal, 50(1), 21-36.

Davis, J., Cook, R., \& Ostenson, J. (2015). Empowering stereotyped readers through self-directed learning. English Journal, 105(1), 42-47.

Garrison, H. (2008). Adolescents' perceptions of the sociocultural construct of disability when responding to literature: "Of mice and men." (Doctoral dissertation). ProQuest. (Order No. 3302114)

Hayn, J. A., Hazlett, L. A., \& Sweeney, W. J. (2009). Facilitating inclusion: Young adult literature as a tool. English Leadership Quarterly, 31(4), 8-11.

Hayn, J. A., Clemmons, K. R., \& Garner, L. (2013). Transforming perceptions of English Language Learners: Action research with Mexican WhiteBoy. The SIGNAL Journal, $36(2), 12-14$. 
Hedges, S. H., Hume, K., Kirby, A.V., Pace, S., \& Sreckovic, M. A. (2014). "Falling through the cracks": Challenges for high school students with autism spectrum disorder. High School Journal, 98(1), 64-82.

Henderson, J. (2009). Disabilities, attitudes, and young adult literature: Teaching Freak the Mighty in a regular education language arts class. English Leadership Quarterly, 31(4), 12-14.

Hill, C. (2009). Birthing dialogues: Using The First Part Last in a health class. The ALAN Review 37(1), 29-34.

Humphrey, N., \& Symes, W. (2010). Perceptions of social support and experience of bullying among pupils with autism spectrum disorders in mainstream secondary schools. European Journal of Special Needs Education, 25(1), 77-91.

Juliani, Marcus. (2013). Treacher Collins Syndrome [Prezi presentation]. Retrieved from https://prezi.com/xvyv2qsj1 feo/treacher-collins-syndrome/

Kennedy, T. M., \& Menten, T. (2010). Reading, writing, and thinking about disability issues: Five activities for the classroom. The English Journal, 100(2), 61-67.

Longmore, P. K., \& Goldberger, D. (2000). The league of the physically handicapped and the Great Depression: A case study in the new disability history. The Journal of American History, 87(3), 888-922.

Marsh, S. T. (2008). Effects of labeling: Teacher perceptions and attitudes toward students with special needs (Doctoral dissertation). ProQuest. (Order no. 3274999)

McLeskey, J., Waldron, N. L. (2011). Educational programs for elementary students with learning disabilities: Can they be both effective and inclusive? Learning Disabilities Research and Practice, 26(1), 46-57.

Nachowitz, M. (2015). How Sara got her voice back: The importance of tentativeness. English Journal, 105(1), 35-41.

NPR Staff. (2013). How one unkind moment gave way to Wonder. All Things Considered. Retrieved from: http://www.npr.org/2013/09/12/221005752/howone-unkind-moment-gave-way-to-wonder

Palacio, R. J. (2012). Wonder. New York, NY: Knopf.

Reid, E. P. (2010). The outcast comes in: Grappling with physical disability in the Literacy classroom. The English Journal, 100(2), 105-108. 
Malo-Juvera, V. (2014). Speak: The effect of literary instruction on adolescents' rape myth acceptance. Research in the Teaching of English, 48(4), 407-427.

Stringer, E. T. (2013). Action Research ( $4^{\text {th }}$ ed.). Los Angeles, CA: Sage.

U.S. Department of Education (2011). Individuals with Disabilities Education Act (IDEA) data. Washington, DC: Author.

Wilhelm, J.D. (2010). Next steps in the journey: Literacy and neuroplasticity: Transforming our perspectives and ourselves. Voices from the Middle, 17(4), $37-40$. 